\begin{tabular}{|l|l|l|}
\hline \multicolumn{2}{|c|}{ PublisherInfo } \\
\hline \hline PublisherName & $:$ & BioMed Central \\
\hline \hline PublisherLocation & $:$ & London \\
\hline \hline PublisherImprintName & $:$ & BioMed Central \\
\hline \hline
\end{tabular}

\title{
Theraputic Hypothermia for cerebral protection after Cardiac arrest
}

\begin{tabular}{||l|l|l||}
\hline \multicolumn{3}{|c||}{ ArticleInfo } \\
\hline \hline ArticleID & $:$ & 4327 \\
\hline \hline ArticleDOI & $:$ & $10.1186 /$ ccf-2002-76605 \\
\hline \hline ArticleCitationID & $:$ & 76605 \\
\hline \hline ArticleSequenceNumber & $:$ & 27 \\
\hline \hline ArticleCategory & $:$ & Paper Report \\
\hline \hline ArticleFirstPage & $:$ & 1 \\
\hline \hline ArticleLastPage & $:$ & 3 \\
\hline \hline & & RegistrationDate $: 2002-3-21$ \\
ArticleHistory & $:$ & Received \\
& Accepted & 2002-3-21 \\
& 2002-4-8 \\
\hline \hline ArticleCopyright & $:$ & Biomed Central Ltd2002 \\
\hline \hline
\end{tabular}




\begin{tabular}{|l|l|l||}
\hline ArticleGrants & $:$ & \\
\hline \hline ArticleContext & $:$ & 1305466 \\
\hline
\end{tabular}

Michael DePietro, ${ }^{\text {Aff1 }}$

Aff1 Christiana Hospital, Delaware, USA

\section{Keywords}

Cardiac arrest, ventricular fibrillation, ventricular tachycardia, hypoxic-ischemic injury, hypothermia

\section{Context}

Neurologic injury after sudden cardiac arrest is common and has long been a subject of clinical interest. As pointed out by the authors several studies in animal models, particularly canines, have shown that mild to moderate hypothermia attenuates hypoxic-ischemic injury and some preliminary human studies have suggested similar protection. The authors performed this randomized trial to determine if the induction of mild hypothermia (32-34 degrees Celsius) would improve neurologic outcome after out of hospital cardiac arrest secondary to ventricular dysrhythmias.

\section{Significant findings}

The study randomized patients who sustained a witnessed cardiac arrest secondary to ventricular tachycardia or fibrillation and where successfully resuscitated within 60 minutes to therapy with induced hypothermia to a goal temp of 32-34 degrees celsius, or standard support. Of 3551 screened patients, 3246 were excluded. 275 enrolled, 137 randomized to the hypothermia group, 138 to the control. 14 patients left the study early: Six secondary to death, three due to hemodynamic instability, and 5 for other reasons. In the treatment group goal temperatures where reached at a mean time of $8 \mathrm{hrs}$. More patients in the hypothermia group had a favorable outcome (Cerebral performance score of 1 or 2$)(55 \%$ vs $39 \%)(\mathrm{RR}=1.4, \mathrm{CI}=1.08-1.81)$. Similarly the risk of death was less in the hypothermia group $(\mathrm{RR}=.75, \mathrm{CI}=.58-.95)$. There was no significant difference between the complication rates in the two groups. The authors conclude induced mild hypothermia can result in improved neurologic outcome and survival after cardiac arrest secondary to ventricular dysrhythmias. 


\section{Comments}

This is a very well done study which clearly confirms that hypothermia after cardiac arrest can improve outcome, and in fact can be a feasible tool in the clinical setting. The results are not entirely suprising given the well known neuroprotective effects in similar clinical settings, such as near drowning, or intraoperatively during induced hypothermic circulatory arrest for certain surgical procedures, such as clipping of giant basilar artery aneurysms. The major remaining challenges will be in determining if hypothermia is of value in a broader range of clinical situations (ie arrests associated with other rhythms, or after trauma, pulmonary embolus etc.), as well as determining the optimal speed and degree of cooling. Finally, like many new interventions there will likely be logistical difficulties in having practicing physicians widely adopt this therapy.

\section{Methods}

The study randomized adult patients who sustained a witnessed cardiac arrest, and had initial resuscitation no later than 15 minutes after the arrest, and return of a perfusing rhythm within 60 minutes. To be included in the study the presenting rhythm must have been ventricular tachycardia or fibrillation. Patients were excluded if they had post arrest hemodynamic instabilit (MAP $<60 \mathrm{mmHg}$ ), hypoxia (arterial O2sat $<85 \%$ ), coagulopathy, pregnancy, or sedating drugs. Study patients were randomized to standard care, or standard care plus external cooling with cooling blankets and ice packs, if necessary, to reach a goal temperature of 32-34 Degrees C, which was maintained for $24 \mathrm{hrs}$ followed by passive rewarming. Primary outcome was neurologic function as graded by the Pittsburgh Cerebral performance Category scale $(1=$ good, $5=$ death $)$ at 6 months after the arrest.

\section{References}

1. The Hypothermia After Cardiac Arrest Study Group : Mild Theraputic Hypothermia to Improve the Neurologic Outcome After Cardiac Arrest. New England Journal of Medicine. 2002, 346: 549-556. 